\title{
LSW-177 and LSW-194: Red-fleshed Watermelon Lines with Low-total Soluble Solids
}

\author{
Angela R. Davis ${ }^{1}$ and Penelope Perkins-Veazie \\ U.S. Department of Agriculture, Agricultural Research Service, South \\ Central Agricultural Research Laboratory, P.O. Box 159, Highway 3 West, \\ Lane, OK 74555
}

\section{Julie Collins \\ Eastern Oklahoma State College, Wilburton, OK 74578}

\section{Amnon Levi}

U.S. Department of Agriculture, Agricultural Research Service, U.S. Vegetable Laboratory, Charleston, SC 29414

Additional index words. Citrullus lanatus, taste test, low carbohydrate, diabetes, low sugar

Increasing percent fruit total soluble solids (TSS) content has been a priority for many breeding programs. Perkins-Veazie et al. (2006) reported that the TSS content of modern watermelon [Citrullus lanatus var. lanatus (Thunb.) Matsum. \& Nakai] cultivars are significantly higher than their heirloom counterparts $(\approx 11 \%$ TSS compared with less than $10 \%$ TSS, respectively). Because of their high TSS and low fiber content, watermelons are considered high-glycemic index foods (Foster-Powell et al., 2002). Several countries recommend low-glycemic index foods for people with diabetes to prevent postprandial glycemia and weight gain (Foster-Powell et al., 2002; Pi-Sunyer, 2002). Additionally, the World Health Organization and the Food and Agriculture Organization endorse the glycemic index system for classifying carbohydrate foods (Foster-Powell et al., 2002; Ludwig and Eckel, 2002). It is estimated that there are 20.8 million people in

Received for publication 6 July 2007. Accepted for publication 2 Nov. 2007.

Mention of trade names or commercial products in this article is solely for the purpose of providing specific information and does not imply recommendation or endorsement by the U.S. Department of Agriculture. All programs and services of the U.S. Department of Agriculture are offered on a nondiscriminatory basis without regard to race, color, national origin, religion, sex, age, marital status, or handicap. The article cited was prepared by a USDA employee as part of his or her official duties. Copyright protection under U.S. copyright law is not available for such works. Accordingly, there is no copyright to transfer. The fact that the private publication in which the article appears is itself copyrighted does not affect the material of the U.S. Government, which can be freely reproduced by the public.

We thank Amy Helms, Anthony Dillard, Bill Anderson, and Shelia Magby for providing valuable technical support.

${ }^{1}$ To whom reprint requests should be addressed; e-mail adavis-usda@lane-ag.org the United States with diabetes (Centers for Disease Control and Prevention, 2005). Although watermelon is a high-glycemic food, it is a good source of lycopene (Di Mascio et al., 1989; Perkins-Veazie et al., 2006; Tomes et al., 1963), vitamin A, and potassium (USDA, ARS, 2006). The main objective of this research was to develop watermelon varieties that have a firm, crisp, red (lycopene-containing) flesh and very low TSS for consumers interested in fruit with low sugar and carbohydrate content. In this article, the Agricultural Research Service of the U.S. Department of Agriculture announces the release of LSW-177 and LSW-194, watermelon lines that incorporate full color and low TSS content.

\section{Origin}

Abd El-Hafez et al. (1985) showed that percent TSS was positively associated with flesh color. Thus, we were interested in determining if a critical TSS concentration is necessary for color development in watermelon flesh. Experiments were performed in the spring of 2000 to evaluate quality phenotypes of watermelon lines from the U.S. PI collection of Citrullus spp. We correlated TSS to color development (data not shown). These experiments demonstrated that pigment (red, pink, or yellow) in watermelon flesh highly correlates to TSS content. Nonpigmented fruits usually had low TSS and pigmented fruits invariably had high TSS. In a few individual fruit, however, pigment was noted in low-TSS fruit. In pigmented fruit from one plant, TSS content was very low $(3.1 \%)$. This observation suggested that development of a pigmented low-TSS watermelon line was feasible.

Efforts to develop LSW-177 and LSW194 began in 2001, 1 year after our breeding plots and neighboring fields were planted with multiple commercial varieties and several C. lanatus var. lanatus and C. lanatus var. citroides (L.H. Bailey) Mansf. PI lines.
Seeds from an escaped, open-pollinated C. lanatus var. lanatus exhibiting low TSS, and very firm intense yellow flesh, discovered in a field near our breeding plots at Lane, OK, in the Fall of 2001, were used to develop LSW-177 and LSW-194. We further developed these lines to impart firm, crisp, red, lycopene-containing flesh with much lower percent TSS than commercially available watermelon cultivars. Controlled self-pollinations of plants from the original seeds collected from the escaped plant were initiated in the Winter of 2003 in a greenhouse. Fruits from nine progeny plants were analyzed for TSS and flesh pigmentation (based on a visual color rating). The three fruits with the highest red pigmentation and lowest TSS were selected and grown in a greenhouse with controlled pollinations. Fruits were selected for high pigmentation and low TSS with controlled self-pollinations for five generations for LSW-177 and four generations for LSW-194. At each generation, seeds were collected from the fruits with the best overall appearance, lowest TSS, and highest lycopene content. At this point, the fruit phenotypes appeared to be fixed, so another greenhouse self-pollination during the Fall of 2006 was performed and the seeds from multiple fruits were bulked to produce $\mathrm{S}_{6}$ derived LSW-177 and S $_{5}$-derived LSW-194 seeds.

\section{Plant Characteristics}

Approximately $40 \mathrm{~S}_{5}$ LSW-177 and $\mathrm{S}_{4}$ LSW-194 plants from each line were evaluated during the summer of 2006 in Lane, OK. Transplants were planted $1 \mathrm{~m}$ apart in one row of a nonreplicated field. Both lines demonstrated uniform fruit characteristics within the line and produced $\approx 2$ fruits per plant.

Field experiments at Lane, OK, in 2005 and 2006 showed that LSW-177 and LSW194 are midseason ( $72 \mathrm{~d}$ until first ripe fruit) monoecious watermelon. Typical LSW-177 and LSW-194 plants produce small $2.2 \pm 0.8$ $\mathrm{kg}$ (68 fruit tested) and $1.6 \pm 0.7 \mathrm{~kg}$ (25 fruit tested) fruits, respectively. LSW-177 produces an elongated fruit with a dark green rind and dark green stripes, similar to 'Sangria' (Fig. 1). LSW-194 tends to have a sharp blossom end and blocky stem end; it has a medium green rind with dark green stripes (Fig. 2). Both lines have firm pink flesh with average lycopene content of $24.4 \pm 9.1 \mu \mathrm{g} \cdot \mathrm{g}^{-1}$ (61 fruit tested) for LSW-177 and 29.3 \pm 6.1 (12 fruit tested) for LSW-194. This is slightly lower than 'Black Diamond' $\left[33.8 \pm 4.5 \mu \mathrm{g} \cdot \mathrm{g}^{-1}\right.$ (20 fruit tested)] averaged over 4 years in our Lane, OK, fields (Perkins-Veazie et al., 2006). The average percent TSS for ripe fruits was $5.5 \% \pm 1.2 \%$ (61 fruit tested) for LSW-177 and $6.9 \pm 1.2 \%$ (12 fruit tested) for LSW-194. TSS was tested using a digital refractometer (Atago model PR 100, Gardiner, NY) and lycopene was measured as described by Davis et al. (2003). Table 1 lists TSS and lycopene content for LSW-177, LSW-194, and other watermelon lines. 


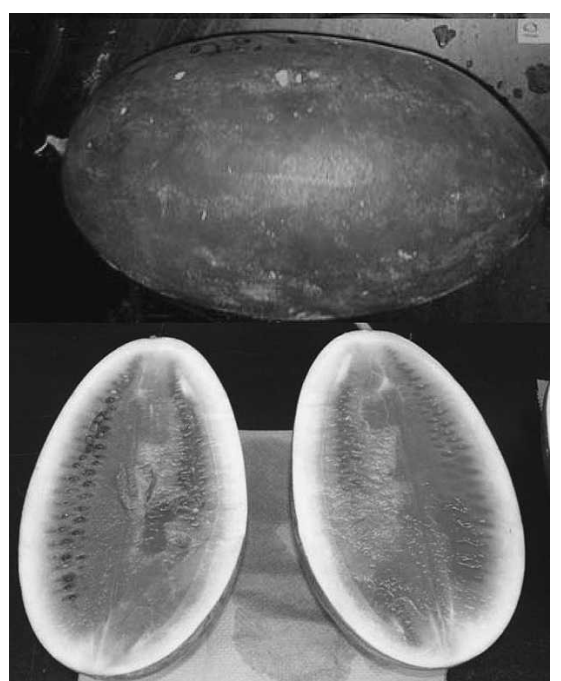

Fig. 1. Ripe LSW-177 fruit showing typical fruit shape and rind pattern (top) and typical rind thickness and red flesh color (bottom).

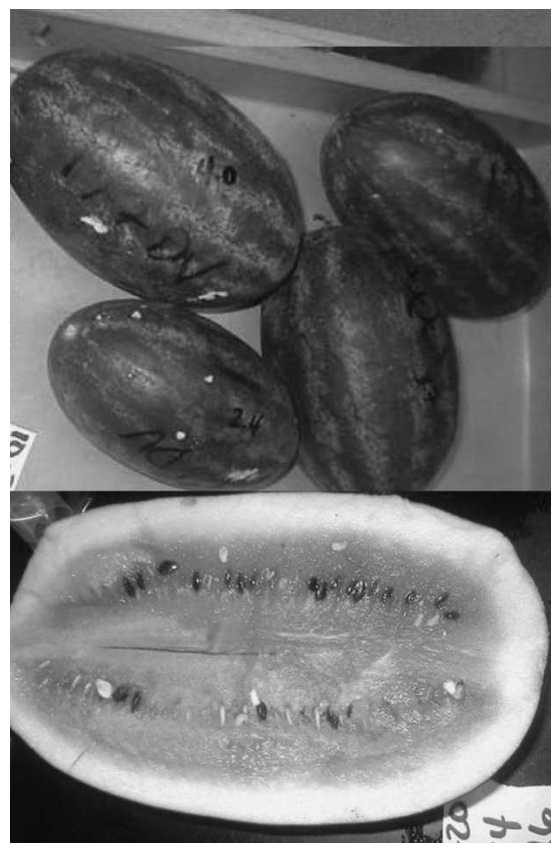

Fig. 2. Ripe LSW-194 fruit showing typical fruit shape and rind pattern (top) and typical rind thickness and red flesh color (bottom).

In 2005 , a consumer acceptability study was performed on LSW-177 watermelon grown at Lane, OK (Collins et al., 2006). This study showed that artificially sweetened lowTSS fruit was comparable to the conventional store-bought full TSS watermelon control ('Sangria' type) in all quantitative and qualitative factors, including taste acceptability, carotenoids, and $\mathrm{pH}$, but was lower in TSS content. This study demonstrated that a lowTSS watermelon, which contains lycopene, a powerful antioxidant, is a palatable fruit choice for individuals who must restrict sugar or total carbohydrate intake.

Table 1. Total lycopene concentration and total soluble solids content of ripe watermelon lines from Lane, OK, grown from 2002 to 2006.

\begin{tabular}{|c|c|c|c|c|}
\hline & $\begin{array}{c}\text { Total } \\
\text { no. of fruit } \\
\text { sampled }\end{array}$ & $\begin{array}{c}\text { Type of } \\
\text { watermelon }^{z}\end{array}$ & $\begin{array}{l}\text { Total soluble } \\
\text { solids } \\
\text { content (\%) }\end{array}$ & $\begin{array}{c}\text { Total } \\
\text { lycopene } \\
\left(\mu \mathrm{g} \cdot \mathrm{g}^{-1}\right)\end{array}$ \\
\hline LSW-177 & 61 & $\mathrm{OP}$ & $5.5 \pm 1.2$ & $24.4 \pm 9.1$ \\
\hline LSW-194 & 12 & $\mathrm{OP}$ & $6.9 \pm 1.2$ & $29.3 \pm 6.1$ \\
\hline Early Moonbeam & 18 & $\mathrm{OP}$ & $8.8 \pm 0.8$ & $\mathrm{NA}^{\mathrm{x}}$ \\
\hline MSW-28y & 59 & $\mathrm{OP}$ & $9.0 \pm 1.1$ & $66.0 \pm 9.9$ \\
\hline Black Diamond & 20 & OP & $9.7 \pm 0.9$ & $33.8 \pm 4.5$ \\
\hline Sugar Baby & 13 & OP & $9.8 \pm 1.1$ & $33.6 \pm 9.2$ \\
\hline Dixie Lee & 20 & OP & $10.3 \pm 1.1$ & $68.1 \pm 9.1$ \\
\hline Triple Crown & 134 & $3 n$ & $10.4 \pm 1.4$ & $52.0 \pm 13.7$ \\
\hline Allsweet & 113 & $\mathrm{OP}$ & $10.8 \pm 1.0$ & $45.6 \pm 7.9$ \\
\hline Tri-X 313 & 40 & $3 \mathrm{n}$ & $11.2 \pm 0.6$ & $64.1 \pm 7.0$ \\
\hline Sweet Favorite & 34 & F1 & $11.5 \pm 0.8$ & $65.4 \pm 9.5$ \\
\hline
\end{tabular}

${ }^{\mathrm{z}} \mathrm{F} 1$, hybrid; OP, open-pollinated, 3n, triploid.

${ }^{y}$ Medium sugar watermelon line released by Davis et al., 2007.

${ }^{x}$ Yellow-fleshed fruits do not contain lycopene.

NA $=$ Not applicable.

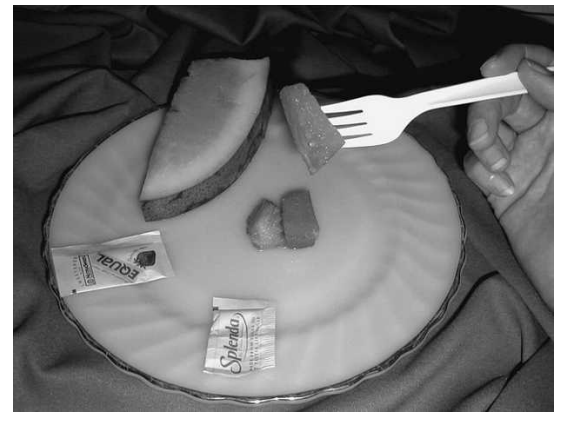

Fig. 3. Ripe low-total soluble solid watermelon fruit showing a serving suggestion.

LSW-177 and LSW-194 are specialty market watermelons with a low-TSS fruit for consumers interested in reduced carbohydrate diets. A sprinkle of artificial sweetener can be used to offer the same refreshing watermelon flavor and sweetness of fullsugar varieties (Fig. 3). LSW-177 and LSW-194 will be useful for producers growing for niche and specialty markets, home gardeners, and plant breeders who develop germplasm for niche and specialty markets.

\section{Availability}

Small samples of LSW-177 and LSW-194 seeds are available to research personnel and plant breeders who make a written request to Dr. Angela R. Davis, South Central Agricultural Research Laboratory, P.O. Box 159, Lane, OK 74555 (e-mail: adavis-usda@laneag.org). LSW-177 and LSW-194 seeds will be submitted to the National Plant Germplasm System where they will be available for research purposes, including the development and commercialization of new cultivars. It is requested that appropriate recognition of the source be given when this germplasm contributes to research or development of a new breeding line or cultivar.

\section{Literature Cited}

Abd El-Hafez, A.A., A.K. Gaafer, and A.M.M. Allam. 1985. Inheritance of flesh colour, seed coat cracks and total soluble solids in watermelon and their genetic relations. II. Quantitative characters and the association between various characters. Acta Agronomica Academiae Scientiarum Hungaricae 34:84-89.

Centers for Disease Control and Prevention. National diabetes fact sheet: General information and national estimates on diabetes in the United States. 2005. 7 U.S. Department of Health and Human Services, Centers for Disease Control and Prevention, Atlanta, GA. 18 Apr. 2007. <http://www.diabetes.org/uedocuments/ NationalDiabetesFactSheetRev.pdf/>.

Collins, J.K., A.R. Davis, A. Adams, N. Mannes, and P. Perkins-Veazie. 2006. Consumer acceptability of low sugar watermelon sweetened with non-calorie sweetener by a Native American community. Int. J. Food Sci. Nutr. 57:363-368.

Davis, A.R., W.W. Fish, and P. Perkins-Veazie. 2003. A rapid hexane-free method for analyzing lycopene content in watermelon. J. Food Sci. 68:328-332.

Davis, A.R. and S.R. King. 2007. MSW-28 a full flavor crisp watermelon line with high lycopene and medium brix. HortScience 42:1715-1716.

Di Mascio, P., S. Kaiser, and H. Sies. 1989 Lycopene as the most efficient biological carotenoid singlet oxygen quencher. Arch. Biochem. Biophys. 274:532-538.

Foster-Powell, K., S.H. Holdt, and J.C. BrandMiller. 2002. International table of glycemic index and glycemic load values: 2002. Amer. J. Clin. Nutr. 76:5-56.

Ludwig, D.S. and R.H. Eckel. 2002. The glycemic index at $20 \mathrm{y}$. Amer. J. Clin. Nutr. 76:264S265S.

Perkins-Veazie, P., J.K. Collins, A.R. Davis, and W. Roberts. 2006. Carotenoid content of watermelon cultivars. J. Agr. Food Chem. 54:25932597.

Pi-Sunyer, F.S. 2002. Glycemic index and disease. Amer. J. Clin. Nutr. 76:290S-298S.

Tomes, M.L., K.W. Johnson, and M. Hess. 1963. The carotene pigment content of certain red fleshed watermelons. Proc. Amer. Soc. Hort. Sci. 82:460-464.

U.S. Department of Agriculture, Agricultural Research Service (USDA, ARS). 2006. USDA National Nutrient Database for Standard Reference, Release 19. Nutrient Data Laboratory Home Page. U.S. Dept. Agr., Washington, DC 23 Apr. 2007. <http://www.ars.usda.gov/ba/ bhnrc/ndl/> 